\title{
The efficacy of active warming in preventing unplanned hypothermia during perioperative period in pediatric surgery patients in a tertiary care center
}

\author{
Ganime Esra Soysal $^{1} \cdot$ Arzu Ilce $^{1} \cdot$ Ummuhan Yigit $^{1} \cdot$ Hulya Ozturk $^{\mathbf{2}} \cdot$ Murat Bilgi $^{\mathbf{3}}$ \\ ${ }^{1}$ Surgical Nursing Department, Faculty of Health Sciences, Bolu Abant Izzet Baysal University, Bolu, Turkey \\ ${ }^{2}$ Department of Pediatric Surgery, Faculty of Medicine, Bolu Abant Izzet Baysal University, Bolu, Turkey \\ ${ }^{3}$ Department of Anesthesia and Reanimation, Faculty of Medicine, Bolu Abant Izzet Baysal University, Bolu, Turkey
}

\section{ABSTRACT}

\begin{abstract}
Aim: To investigate the effects of using the active warming method on children with hypothermia in the perioperative period and examining the effects of hypothermia on awakening time, pain, shivering and hospital stay.

Methods: This study included patients 18 years of age and younger who underwent surgery in the pediatric surgery department of a tertiary hospital. The active warming group consisted of 28 patients and the control group consisted of 29 patients. The first group of patients was actively warmed during the surgery and the second group was treated as the control group and did not actively receive any warming therapy. Preoperative body temperatures of the cases were measured. In addition, body temperatures were recorded every 15 minutes in the intraoperative and postoperative periods.
\end{abstract}

Results: There was no statistically significant difference in preoperative body temperature between the control group and the active warming group. When body temperature were examined in the intraoperative period, there was no significant difference between the groups at the first 15 minutes of operation; however, the mean of the body temperature in active warming group was significantly higher than the control group at the $30^{\text {th }}$, $45^{\text {th }}$, and $60^{\text {th }}$ minutes of operation. It was determined that patients in the control group had a longer stay in the hospital and the amount of time for waking at the end of the anesthesia was shorter in the active heating group than in the control group.

Conclusions: The results of our study suggest that active heating with a carbon fiber resistant system is an effective method to prevent unplanned hypothermia in operated children.

Keywords: Body temperature, surgical procedures, hypothermia, active warming, child.

Ganime Esra Soysal, Surgical Nursing

Department, Faculty of Health Sciences, Bolu Abant

Izzet Baysal University, Bolu, Turkey

E-mail: ganimeesrasoysal@gmail.com

Received: 2020-05-13 / Revised: 2020-06-03

Accepted: 2020-07-03 / Published online: 2021-01-01

\section{Introduction}

General anesthesia affects the body's internal temperature in all children undergoing surgery. There is an increased risk of hypothermia, especially in prolonged and open body cavity operations [1]. Heat loss occurs more easily in children [2]. Hypothermia occurs when body temperature drops below $36^{\circ} \mathrm{C}$ in adults and below $36.5{ }^{\circ} \mathrm{C}$ in newborns. Cold stress in newborns is between $36-36.5^{\circ} \mathrm{C}$, moderate hypothermia is considered $32-36^{\circ} \mathrm{C}$ and severe hypothermia is below $32^{\circ} \mathrm{C}[3,4]$. During surgery, heat loss from the body occurs by radiation, convection, conduction and 
evaporation, and radiation and convection make up $85 \%$ of this heat loss [5]. In addition, preterm, low birth weight and sick infants are much more susceptible to hypothermia due to the absence or scarcity of brown adipose tissue, and newborns also have a limited amount of movement, shaking and stretching [6,7]. Therefore, infants and newborns have a higher risk of developing intraoperative hypothermia during surgery. Since thermoregulation centers of babies are not developed, they should be supported in the perioperative period to maintain the hemodynamic state and maintain normal body temperature [8]. In addition, it has been reported that perioperative hypothermia causes wound infections, increases surgical site infections, increases oxygen demand, changes the pharmacokinetics of drugs, impairs coagulation, and causes cardiac arrhythmias and ventilation problems, especially in children [9-12]. Therefore, the quality of care and safety of children who have undergone surgery is very important in the perioperative period.

Passive and active warming methods are used to prevent unplanned hypothermia in the perioperative period. Passive warming methods consist of cotton or wool blankets, stockings, hats, and surgical drapes [13,14]. Active warming techniques include compressed air systems, resistive systems (electric, carbon fiber, jelly coats, etc.), radiant heaters, intravenous fluid, blood and blood products heaters, and heat and moisture exchanger filters [1-14]. There are few studies in the literature on active warming of children in the operating room. In addition, it is not known exactly whether an active warming method will have any effect on preventing unplanned hypothermia in the perioperative period. Therefore, the aim of this study is to investigate the effects of hypothermia on recovery time, pain, shivering, and duration of hospital stay in operated children, and the effects of perioperative active warming on preventing unplanned hypothermia in children.

\section{Materials and Methods}

The study was conducted on 57 cases, who underwent surgery in the pediatric clinic at the University Hospital between October 1, 2016, and December 30, 2016. Ethical approval was obtained from Clinical Trials Ethical Board at Bolu Abant Baysal University (Date and decision number: 2016/17-182). Necessary permissions were obtained from the hospital and families. All procedures performed in studies involving human participants were in accordance with the ethical standards of the institutional and/or national research committee and with the 1964 Helsinki declaration and its later amendments or comparable ethical standards.

We included all children under the age of 18 with normal weight and ranked ASA I-II-III and were operated upon. The exclusion criteria were those who needed intensive care, had infectious diseases, scored ASA IV and above, and had congenital anomalies.

The accidental sampling method was used by the investigator to divide the patients into groups and to prevent bias. The sampling size was determined by power analysis in a computer program. Two groups of 60 patients were placed randomly but patients who did not want to participate were excluded from the groups. For this reason, the control group consisted of 29 patients and the experimental group consisted of 28 patients. The operations included in the study were hernia, hernia + circumcision, neck mass excision, undescended testis + circumcision, cholecystectomy and pyeloplasty. The first group of patients were actively warmed during the perioperative period (Istanbul Medical- Medwarm resistive 
system-W-500D $+80 * 50 \mathrm{~cm}$ or $120 * 50$ ). The system was set to $38^{\circ} \mathrm{C}$ from $40^{\circ} \mathrm{C}$ and disposable mattress covers were used for each patient in order to prevent surgical area infections. The second group was assigned as a control group. As a result of hospital procedures, all children were dressed in surgical gowns until they were taken to surgery. They were then wrapped in green covers. Apart from this, no application was made to the control group.

Body temperatures of all patients were measured with non-contact thermometer from temporal artery at 15 minute intervals during the preoperative, intraoperative and postoperative period. Body temperature measurement of children continued for 3 hours in the recovery room and pediatric clinic after surgery. The hospital staff measuring the patient's body temperature did not know to which group the patients were assigned. Blood pressure, pulse, respiration, $\mathrm{O}_{2}$ saturation and pain scores were evaluated synchronously. Additionally, surgery room ambient temperature $\left({ }^{\circ} \mathrm{C}\right)$, surgery time, IV (intravenous) solution quantity ( $\mathrm{ml})$, type of anesthesia and ASA score were recorded. Visual pain scale (VAS) scale was used for pain measurement. Those whose body temperature was measured below 36 degrees were considered hypothermic.

\section{Statistical analyses}

Continuous data were coded in SPSS (Statistical Package for the Social Sciences) 22.0 program and statistical evaluation was performed with number, percentage, $t$ test, Mann- Whitney $U$ tests and Analysis of Variance tests (ANOVA). The results were assessed within $95 \%$ confidence interval and a $p$ value of $<0.05$ was considered as statistically significant.

\section{Results}

If we look at the identifying characteristics of patients, 57 patients, that consisted of 28 patients in active warming group and 29 patients in control group, were included in the study. The anesthesia technique used was similar in all children. General anesthesia was applied to all patients.

All patients were normothermic before induction. It was determined that age average of all patients was approximately 3.5 years old, the operating room temperature mean was $25.9 \pm 1.3$ ${ }^{\circ} \mathrm{C}$, awakening time from anesthesia was $8.4 \pm 3.0$ minute, and the length of stay in hospital mean was $1.5 \pm 2.5$ day in active warming group. Shivering was seen less frequently in patients who were warmed (Table $1)$.

Hypothermia was observed in $27.6 \%(8: 29)$ of children in the control group during the intraoperative period. In the postoperative period, $13.8 \%(4: 29)$ of the children were hypothermic in the control group. Hypothermia was not observed in children in the active heating group who were given intraoperative heating.

When body temperature was examined in the preoperative period, there was no statistically significant difference between the body temperatures in the control group (X: 36, $88 \pm 0.43$ ) and the active warming group (X: 36 , $80 \pm 0.35)$, indicating that the groups were homogeneous ( $t: .817 ; p \geq 05)$. The primary outcomes when body temperature were examined in the intraoperative period was that there was no significant difference between the groups at the first 15 minutes of operation ( $p \geq$ 0.05 ), but the active warming group was significantly higher than the control group in 30th, 45th, 60th minutes in intraoperative period $(p \leq 0.05)$, (Figure 1). 
Table 1. Identifying characteristics of patients (n: 57).

\begin{tabular}{|c|c|c|c|c|c|c|c|}
\hline \multirow{2}{*}{ Groups* } & & \multicolumn{2}{|c|}{$\begin{array}{c}A \\
(n: 28)\end{array}$} & \multicolumn{2}{|c|}{$\begin{array}{c}C \\
(n: 29)\end{array}$} & \multirow{2}{*}{\multicolumn{2}{|c|}{$\begin{array}{c}\text { Statistical } \\
\text { Analysis } \\
\end{array}$}} \\
\hline & & n & $\%$ & n & $\%$ & & \\
\hline \multirow{2}{*}{ Gender } & Female & 7 & 12.3 & 10 & 17.5 & \multirow{2}{*}{\multicolumn{2}{|c|}{$\begin{array}{c}X^{2}: .612 \\
p: .43\end{array}$}} \\
\hline & Male & 21 & 36.8 & 19 & 33.3 & & \\
\hline \multirow{2}{*}{$\begin{array}{l}\text { Age } \\
\text { (year) }\end{array}$} & $0-1$ & 9 & 15.8 & 13 & 22.8 & \multirow{2}{*}{\multicolumn{2}{|c|}{$\begin{array}{l}X^{2}: .967 \\
p: .23\end{array}$}} \\
\hline & $2-18$ & 19 & 33.3 & 16 & 28.1 & & \\
\hline \multirow{3}{*}{ ASA } & I & 24 & 42.1 & 25 & 43.9 & \multirow{3}{*}{\multicolumn{2}{|c|}{$\begin{array}{l}X^{2}: .536 \\
p: .76\end{array}$}} \\
\hline & II & 3 & 5.3 & 2 & 3.5 & & \\
\hline & III & 1 & 1.8 & 2 & 3.5 & & \\
\hline \multirow{2}{*}{$\begin{array}{l}\text { Operation time } \\
\text { (minute) }\end{array}$} & $0-60$ & 21 & 36.8 & 25 & 43.9 & \multirow{2}{*}{\multicolumn{2}{|c|}{$\begin{array}{c}X^{2}: 1.149 \\
p: .23\end{array}$}} \\
\hline & Over 60 & 7 & 12.3 & 4 & 7.0 & & \\
\hline \multirow{3}{*}{ Duration of fasting (hour) } & $0-4$ & 1 & 1.8 & 2 & 3.6 & \multirow{3}{*}{\multicolumn{2}{|c|}{$\begin{array}{l}X^{2}: 2.987 \\
p: .22\end{array}$}} \\
\hline & $5-8$ & 19 & 33.9 & 23 & 41.1 & & \\
\hline & Over 8 & 8 & 14.3 & 3 & 5.4 & & \\
\hline \multirow[t]{2}{*}{ Shivering } & Yes & 1 & 1.8 & 13 & 22.8 & \multirow{2}{*}{\multicolumn{2}{|c|}{$\begin{array}{c}X^{2}: .13 .086 \\
p: .001^{* *}\end{array}$}} \\
\hline & No & 27 & 47.4 & 16 & 28.1 & & \\
\hline \multirow{3}{*}{ Sum } & & $\mathbf{n}$ & $\%$ & $\mathbf{n}$ & $\%$ & $\mathbf{n}$ & $\%$ \\
\hline & & 28 & 49.1 & 29 & 50.9 & 57 & 100 \\
\hline & & \multicolumn{2}{|c|}{ Mean \pm SD } & \multicolumn{2}{|c|}{ Mean \pm SD } & \multicolumn{2}{|c|}{$\begin{array}{c}\text { Statistical } \\
\text { Analysis }\end{array}$} \\
\hline Operating room temperature & & $25.9 \pm 2.0$ & & $26.7 \pm 1.3$ & & \multicolumn{2}{|c|}{$\begin{array}{l}t: 1.853 \\
p: .06^{* *}\end{array}$} \\
\hline $\begin{array}{l}\text { Awakening time from anesthesia } \\
\text { (minute) }\end{array}$ & & \multicolumn{2}{|l|}{$8.4 \pm 3.0$} & \multicolumn{2}{|l|}{$10.7 \pm 3.0$} & \multicolumn{2}{|c|}{$\begin{array}{l}t: 2.832 \\
p: .006^{* *}\end{array}$} \\
\hline Length of stay in hospital (day) & & $1.5 \pm 2.5$ & & $1.8 \pm 1.5$ & & & 281.0 \\
\hline
\end{tabular}

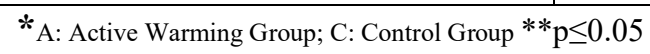

\section{Preoperative and Intraoperative Period}

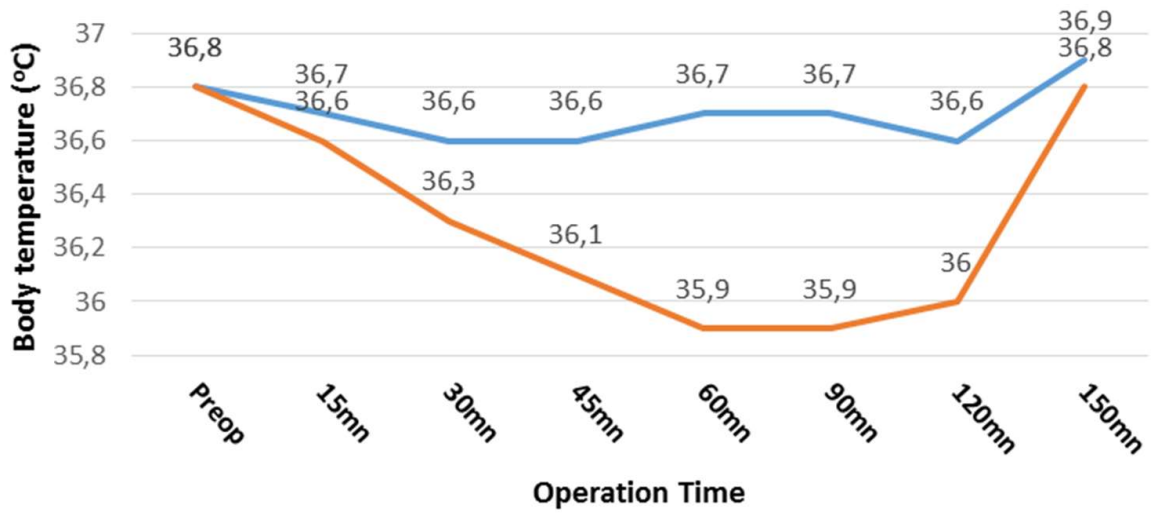

Figure 1. Change of body temperature during preoperative and intraoperative period. *Preop: Body temperature at the time of admissiin in operating room. 


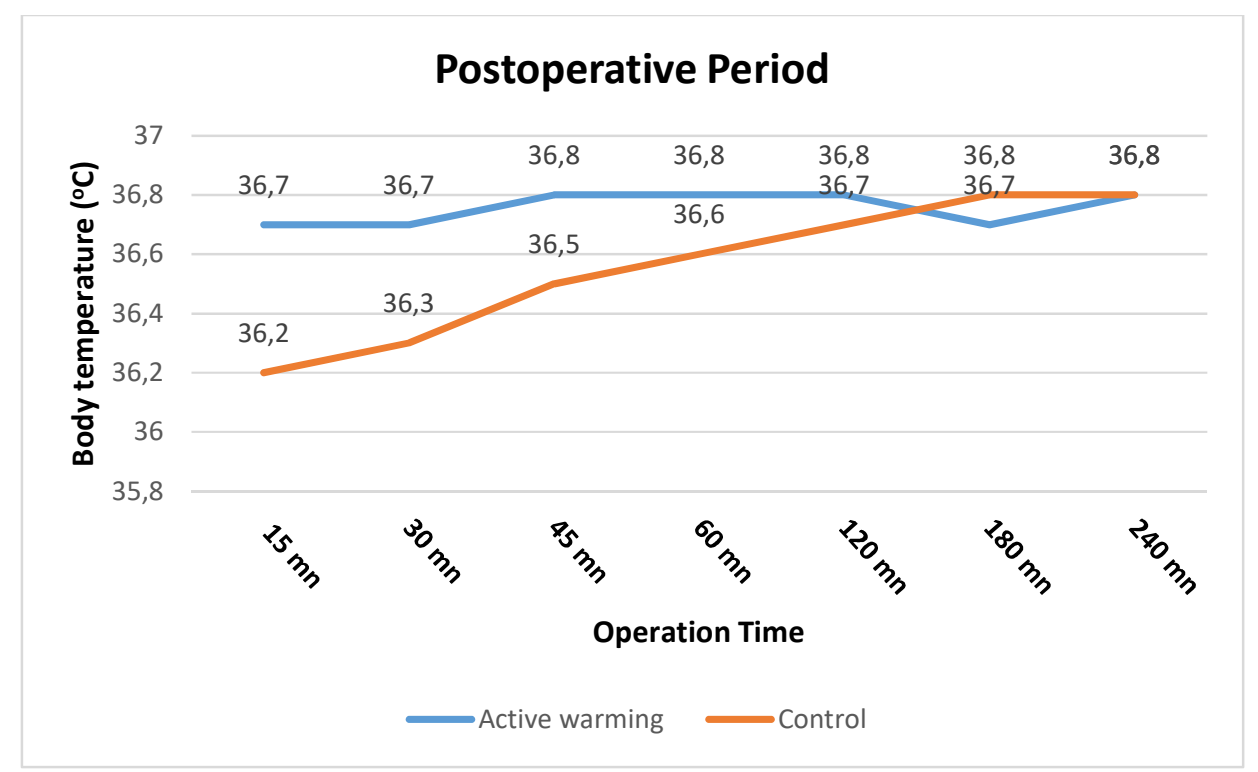

Figure 2. Change of body temperature during postoperative period.

In the postoperative period, there was no statistically significant difference in the body temperatures between the control group and the active warming group ( $p \geq 05$ ), (Figure 2).

When pain was examined in the postoperative period, it was observed that the pain mean score of control group was significantly higher than the pain mean score of the active warming group only in the 15 th minute $(p \leq 0.05)$ (Table 2).

Table 2. Pain in the postoperative period.

\begin{tabular}{|c|c|c|c|c|}
\hline \multicolumn{2}{|c|}{ Groups } & $\mathbf{A}$ & $\mathbf{C}$ & $p^{* *}$ \\
\hline \multirow{7}{*}{ 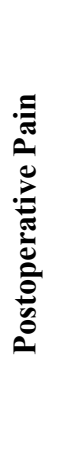 } & $15 \mathrm{mn}$ & $6.0 \pm 3.4$ & $3.5 \pm 3.2$ & .006 \\
\hline & $30 \mathrm{mn}$ & $3.2 \pm 3.1$ & $2.5 \pm 3.2$ & .20 \\
\hline & $45 \mathrm{mn}$ & $1.5 \pm 1.9$ & $0.8 \pm 1.8$ & .11 \\
\hline & 1 hour & $0.7 \pm 1.3$ & $0.2 \pm 0.8$ & .10 \\
\hline & 2 hour & $0.4 \pm 0.9$ & $0.5 \pm 1.2$ & .94 \\
\hline & 3 hour & $0.2 \pm 0.8$ & $0.4 \pm 0.9$ & .22 \\
\hline & 4 hour & $0.1 \pm 0.5$ & $0.07 \pm 0.3$ & .57 \\
\hline
\end{tabular}

Values: Mean $\pm S D,{ }^{*}$ A: Active Warming Group; C: Control Group $* * p \leq 0.05$
Shivering were observed in $44.8 \%$ of patients in the control group and $3.6 \%$ of patients in the active warming group; the difference between the groups was significant $\left(X^{2}: 13.086 ; p \leq 001\right)$. It was determined that patients in the control group had a longer stay in the hospital (MannWhitney $U: 281000 ; p \leq 0.05)$ and the amount of time waking at the end of the anesthesia was shorter in the active warming group than the control group $(t: 2,832 ; p \leq 05)$.

\section{Discussion}

Hypothermia is an important complication during the perioperative period $[15,16]$. Body temperature should be followed very carefully in both the intraoperative and postoperative period [17]. Healthcare professionals should know the underlying causes of hypothermia and the associated risk factors and also know the strategies to prevent or treat hypothermia. Nowadays, there are many ways that clinicians may help reduce hypothermia in children. It is reported that the use of an active patient warming for children under anesthesia is an effective method to protect patients from 
unwanted perioperative hypothermia [18]. Tander states that children's body temperature drops within ten minutes after induction of anesthesia [9]. Continuous monitoring of core temperature is necessary to prevent hyperthermia.

Ying $\mathrm{Pu}$ et al. [19] reported that they warmed patients intraoperatively with warming blanket in gastrointestinal surgery; after the operation, heated patients were found to have lower pain than patients in the control group. Pain and delayed recovery are defined in relation to perioperative hypothermia [16]. Studies have reported that prevention from hypothermia reduced pain after surgery after the operation, especially in children, and this is confirmed by our study because the control group had higher pain scores in our study.

Gharavifard et al. [20] reported that awakening time of children from general anesthesia was $15.30 \pm 5.27$ minutes after surgery and it was observed that the body temperatures of the children decreased during the surgery in their study. In our study, awakening time of children from general anesthesia was $10.7 \pm 3.0$ minutes in control group. This value was found to be significantly higher than the awakening time of the warming group (8.4 \pm 3.0$)$.

It was reported that normal thermoregulation should be provided in children, otherwise the hospitalization will be prolonged. In our study, it was seen that the control group stayed in the hospital longer than the warming patients.

Radiant heaters are not suitable for use in operating rooms. It also has its difficulties in when used for breastfeeding babies. The blanket or shield can be used for children [21]. The resistive heating system that was used in this study had a shield. Children can be transferred from one place to another using this system.
Studies have clearly shown the benefits of using the active warming systems in infants and children [22]. Sultan et al. [23] reported that the active warming after birth lowered the perioperative temperature and the incidence of hypothermia and shivering was decreased. In this study, postoperative shivering after intraoperative active warming was significantly lower than other patients.

Shen et al. reported that they found the incidence of postoperative hypothermia $5 \%$ in their study [24]. In this study, the postoperative hypothermia rate in the control group was $13.8 \%$. No hypothermia was observed in children with the active warming group.

In the literature, force-air warming devices, radiant warmers, and circulating water mattresses are reported as a main method for perioperative hypothermia management [24]. Resistive heating method can be added to these active warming methods. It is also important that such materials can be cleaned due to the recent COVID 19 pandemic. In developing countries, the use of disposable covers cannot be applied due to cost. The resistive system with carbon fiber used in this study is recommended because it is a cost-effective method since it can be disinfected.

In addition to all these, if hypothermia develops, the children must be dressed and covered with a heated blanket and they should be heated by appropriate methods, such as active warmimg medhods. Anesthesia team, who provide perioperative care, are responsible for ensuring and maintaining temperature control during the surgical process [25]. Children' body temperature should be measured every 2 hours until it rises to more than $36.5^{\circ} \mathrm{C}$ [26].

The limitations of this study are the fact that the body surface areas of the patients could not be 
measured and the operating room temperature could not be fixed.

\section{Conclusions}

Consequently, active warming with a carbon fiber resistive system was found to be an effective method for the prevention of unplanned hypothermia in children. It was also determined that there was less shivering, the amount of time for waking the end of the anesthesia were faster and discharge times were shorter in active warming group.

Funding: There is no financial support and sponsorship

Conflict of Interest: The authors declare that they have no conflict of interest.

Ethical statement: The study was conducted in accordance with the ethical approval of the University Ethics Committee (Date and decision number: 2016/17-182).

\section{ORCID iD of the author(s)}

Ganime Esra Soysal / 0000-0002-8291-4310

Arzu Ilce / 0000-0001-8428-9865

Ummuhan Yigit / 0000-0001-6791-2299

Hulya Ozturk / 0000-0003-1719-4924

Murat Bilgi / 0000-0002-9001-2309

\section{Copyrights: (C) 2021@author (s).}

This is an open access article distributed under the terms of the Creative Commons Attribution License (CC BY 4.0), which permits unrestricted use, distribution, and reproduction in any medium, provided the original author(s) and source are credited and that the original publication in this journal is cited, in accordance with accepted academic practice. No use, distribution or reproduction is permitted which does not comply with these terms.

\section{References}

[1]Cassey JG, Peter JA, G11 ES, et al. The safety and effectiveness of a modified convection heating system for children during anesthesia. Pediatr Anesth. 2006;16(6):654 62.

[2]The World Health Organisation. The Clinical Use of Blood The Clinical Use of Blood: General Medicine, Paediatrics, Obstetrics Trauma, Anaesthesia. 2017. 1$349 \mathrm{p}$.

[3]Çinar ND, Filiz TM. Neonatal thermoregulation. J Neonatal Nurs. 2006;12(2):69-74.

[4]Eras Z, Bingöler Pekcici EB, Atay G. Mortality and morbidity of premature infants. Medical Journal of Bakırköy. 2011;7(3):85-88.

[5]Collins S, Budds M, Raines C, et al. Risk Factors for Perioperative Hypothermia: A Literature Review. J Perianesthesia Nurs. 2019;34(2):338-46.

[6]Ellis J. Neonatal hypothermia. J Neonatal Nurs. 2005;11:76-82.

[7]Kösa E, Çınar N. Prevent hypothermia in premature infants: use plastic wrap. Balikesir Health Sciences Journal. 2014;3(3):161-65.

[8]Morehouse D, Williams L, Lloyd C. Perioperative hypothermia in NICU infants: its occurrence and impact on infant outcomes. Adv Neonatal Care. 2015;14(3):154-64.

[9]Tander B, Baris S, Karakaya D, et al. Risk factors influencing inadvertent hypothermia in infants and neonates during anesthesia. Paediatr Anaesth. 2005;15(7):574-79.

[10] Sappenfield JW, Hong CM, Galvagno SM. Perioperative temperature measurement and management: moving beyond the Surgical Care Improvement Project. J Anesthesiol Clin Sci. 2013;2(1):1-9. 
[11]Beedle SE, Phillips A, Wiggins S, et al. Preventing Unplanned Perioperative Hypothermia in Children. AORN J. 2017;105(2):170-83.

[12] Walker S, Amin R, Arca MJ, et al. Effects of intraoperative temperatures on postoperative infections in infants and neonates. J Pediatr Surg. 2020;55(1):80-85.

[13] Sessler D. Temperature monitoring and perioperative thermoregulation. Anesthesiology. 2008;109(2):318-38.

[14] Adriani MB, Moriber N. Preoperative forced-air warming combined with intraoperative warming versus intraoperative warming alone in the prevention of hypothermia during gynecologic surgery. AANA J. 2013;81(6):446-51.

[15] Garami A, Ibrahim M, Gilbraith K, et al. Prevent Anesthesia-induced Hypothermia and Decrease. Anesthesiology. 2017;127(5):813-23.

[16] Engorn BM, Kahntroff SL, Frank KM, et al. Perioperative hypothermia in neonatal intensive care unit patients: effectiveness of a thermoregulation intervention and associated risk factors. Paediatr Anaesth. 2017;27(2):196-204.

[17] Soysal GE, Ilce A, Erkol MH. Effect of ““” An Innovative Technology "' Active Warming and Passive Warming on Unplanned Hypothermia During Perioperative Period: Ther Hypothermia Temp Manag. 2018;8(4):216-24.

[18] Witt L, Dennhardt N, Eich C, et al. Prevention of intraoperative hypothermia in neonates and infants: results of a prospective multicenter observational study with a new forced-air warming system with increased warm air flow. Pediatr Anesth. 2013;23(6):469-74.

[19] Pu Y, Cen G, Sun J, et al. Warming with an underbody warming system reduces intraoperative hypothermia in patients undergoing laparoscopic gastrointestinal surgery: A randomized controlled study. Int J Nurs Stud. 2014;51(2):181-89.

[20] Gharavifard M, Peivandi A, Amini S. Evaluation of the Effect of Amino Acid Administration on Hypothermia during General Anesthesia in Hypospadias Surgery on Children Aged 2 to 6 Years. Int J Pediatr. 2014;2(3-1):203-210.

[21] Lyon A. Temperature control in the neonate. Paediatr Child Health (Oxford). 2008;18(4):155-60.

[22] Cassey JG, Armstrong PJ, Smith GE, et al. The safety and effectiveness of a modified convection heating system for children during anesthesia. Pediatr Anesth. 2006;16(6):654-62.

[23] Sultan P, Habib AS, Cho Y, et al. The Effect of patient warming during Caesarean delivery on maternal and neonatal outcomes: A meta-analysis. $\mathrm{Br} \mathrm{J}$ Anaesth. 2015;115(4):500-510.

[24] Shen J, Wang Q, Zhang Y, et al. Combination of warming blanket and prewarmed intravenous infusion is effective for rewarming in infants with postoperative hypothermia in China. Paediatr Anaesth. 2015;25(11):1139-143.

[25] Yurdadur Duman A, Y1lmaz E. Incidence of perioperative hypothermia in orthopaedic surgery and risk factors. Cukurova Med J. 2016;41(4):687-94.

[26] World Health Organisation. Hospital care for children, guidelines for the management of common illnesses with limited resources [Internet]. WHO. 2005. 177-178 p.Available from: http://apps.who.int/iris/bitstream/handle/10 $665 / 43206 / 9241546700$.pdf? sequence $=1$. 